\title{
Research on the Network Public Opinion Pre-warning Based on Analytic Hierarchy Process
}

\author{
Qingguo Wang * \\ School of Management \\ Wuhan University of Technology \\ Wuhan, China \\ wqg1997@163.com \\ *Corresponding author
}

\author{
Shuxia Xie \\ School of Management \\ Wuhan University of Technology \\ Wuhan, China \\ 517482084@qq.com
}

\author{
Yaohua Wang \\ School of Management \\ Wuhan University of Technology \\ Wuhan, China \\ 675801895@qq.com
}

\begin{abstract}
The article constructed a scientific, complete and practical index system about online public opinion after reading a large number of books and articles. Then it obtained the data through questionnaires, using the analytic hierarchy process to analyze the data and calculate weight of the indexes; finally, it evaluated 40 pieces of network public opinion in 2012 by using analytic hierarchy process.
\end{abstract}

Keywords- online public opinion; index system; pre-warning; Analytic Hierarchy Process

\section{INTRODUCTION}

With the rapid development of information technology, the Internet has become the most widely used 'the fourth media for today's influence', after the broadcast, TV, newspaper. Equality, open, hidden, fast, cross temporal and spatial are its characteristics, and the public regard it as one of the most important platform of information acquisition and dissemination. Network become a melting pot of all kinds of ideas, attitudes and opinions, expand remarks channels of ordinary people and to improve the efficiency of information dissemination conducive to the popularity of science and technology and the development of socio-economic, but on the other hand improperly remarks easily initiate a network of public opinion crisis. Therefore, network public opinion must be fast and effective analysis and warning early and eliminate the crisis in the bud, avoid the enlargement of adverse events. Based on this, the paper constructs the network public opinion pre-warning model, and uses AHP method to make assessment of online public opinion pre-warning.

\section{CONSTRUCTION OF INDEX SYSTEM OF ONLINE PUBLIC OPINION PRE-WARNING}

Based on the existing literature, this paper constructs the index system of online public opinion pre-warning (see TABLE I, see the end of the article). The index system is divided into three layers, the first layer is the target layer, and the middle layer is the criterion, the lowest layer is the factor layer, each layer is corresponding to different levels of index. The target layer is corresponding to the first layer index, it is the comprehensive index of network public opinion, and the index reflects the comprehensive situation of network public opinion, the results of the index value directly determines the online public opinion pre-warning level. The second layer index consists of information activity of network public opinion, attention of online public opinion, sentiment of online public opinion, the sensitivity of network public opinion, as the criterion layer index system. Public opinion reflects the characteristics of itself, public opinion propagation is embodied in the development of public opinion, and public opinion is the reaction of public audience to public events. The bottom layer is composed of the factor layer and their corresponding index.

\section{DESIGN OF ONLINE PUBLIC OPINION PRE-WARNING MODEL BASED ON AHP}

AHP is a multi-objective decision making method, it is a combination of qualitative and quantitative research, and it is proposed by Saaty who is an operational research expert of American in the nineteen seventies; it is especially suitable for quantifying qualitative experience of decision makers, AHP can generally be divided into four steps: setting up the hierarchy structure, constructing judgment matrix and assignment, rank ordering (calculate the weight vector) and inspection, the level of total order and inspection.

\section{A. setting up the hierarchy structure}

By using the analytic hierarchy process should first clear the decision problems and make them organized, hierarchical, and establish the hierarchical structure. The hierarchical structure includes target layer, criterion layer and measure layer.

The target layer is the most senior; it is the preset goals of solving the problems. First we analyze the decision problem, 
get the goal to reach, and make the goals as the target layer elements. The target layer elements should be unique, that is, one and only one element. The criterion layer is the middle layer; it represents the rules of achieving the goals. In the complicated decision problems in reality, the guidelines to achieve the goals are usually more, and then it must analyze the relationship between different criterions, find out the main standards and secondary standards of membership, and be hierarchical and grouping. The upper element is composed of the lower elements, and controls the lower elements; the same layer element can be divided into several different groups, the same group elements are subject to upper layer elements with similar properties. Measure layer is for the lowest layer, and it delegates the measures that goals needed to achieve, usually refers to the solution of decision problems below the above criteria.

The decision factors and position of each level is determined, connected by wires to the relationship is the hierarchical structure.

\section{B. constructing judgment matrix and assignment}

After establishing the hierarchical structure, there will be downward subordinate relations criterion as the first element on the left upper corner of the judgment matrix, the subordinate elements in turn toward the back, repeat this step matrix can be obtained. By using the expert scoring method for multiple comparison the importance of judging matrix elements, and used 1-9 scaling method for assignment, as shown in TABLE II

TABLE II. DEFINITION TABLE OF IMPORTANT SCALE

\begin{tabular}{|c|c|}
\hline $\begin{array}{c}\text { Importance of } \\
\text { scale }\end{array}$ & meaning \\
\hline 1 & $\begin{array}{c}\text { Compared with the element } i \text { and element } \\
j \text { are equally important }\end{array}$ \\
\hline 3 & $\begin{array}{c}\text { Element } i \text { compared with element } j, \\
\text { element } i \text { is a little important }\end{array}$ \\
\hline 5 & $\begin{array}{c}\text { Element } i \text { compared with element } j, i \text { is } \\
\text { obviously important }\end{array}$ \\
\hline 7 & $\begin{array}{c}\text { Element } i \text { compared with element } j, i \text { is } \\
\text { strongly important }\end{array}$ \\
\hline 9 & $\begin{array}{c}\text { Element } i \text { compared with element } j, i \text { is } \\
\text { extremely important }\end{array}$ \\
\hline $2,4,6,8$ & Between the above comparison \\
\hline reciprocal & $\begin{array}{c}\text { The reciprocal of the ratio of above } \\
\text { importance comparison }\end{array}$ \\
\hline
\end{tabular}

We issue forty survey questionnaires to the school and the corresponding research institute experts, all questionnaires are collected, the effective questionnaires are thirty-eight, the effective rate of recovery is ninety-five percent. We use Cronbach acoefficient to do reliability test, and analysis results show that the overall Cronbach $\alpha$ coefficient of the questionnaire is between 0.672 to 0.987 , are not less than 0.6 , so it passes the reliability test. Validity test results show that, the KMO value is $0.932, \mathrm{P}$ value is 0.00047 , so the data are suitable for factor analysis; factor analysis results show that all the indexes generate 4 common factors, they explain $82.21 \%$ of the population variance, the factor loading of indexes are between 0.51 to 0.92 , they all are more than 0.4 , so the questionnaire also passes the validity test. Each level of judgment matrix and the results of weight are shown in TABLE III to TABLE X..
TABLE III. A-B LAYER JUDGMENT MATRIX AND WEIGHT COEFFICIENT

\begin{tabular}{|l|l|l|l|l|l|}
\hline $\mathbf{A}$ & \multicolumn{1}{|c|}{$\mathbf{B}_{\mathbf{1}}$} & \multicolumn{1}{|c|}{$\mathbf{B}_{\mathbf{2}}$} & \multicolumn{1}{|c|}{$\mathbf{B}_{\mathbf{3}}$} & \multicolumn{1}{|c|}{$\mathbf{B}_{\mathbf{4}}$} & \multicolumn{1}{|c|}{ Weight $\boldsymbol{W}_{\boldsymbol{i}}$} \\
\hline $\mathbf{B}_{\mathbf{1}}$ & 1 & 7 & 2 & 6 & 0.524 \\
\hline $\mathbf{B}_{\mathbf{2}}$ & $1 / 7$ & 1 & $1 / 5$ & $1 / 3$ & 0.054 \\
\hline $\mathbf{B}_{\mathbf{3}}$ & $1 / 2$ & 5 & 1 & 5 & 0.325 \\
\hline $\mathbf{B}_{\mathbf{4}}$ & $1 / 6$ & 3 & $1 / 5$ & 1 & 0.097 \\
\hline
\end{tabular}

TABLE IV. B $_{1-} C_{i} \quad$ (I=1,2) LAYER JUDGMENT MATRIX AND WEIGHT COEFFICIENT

\begin{tabular}{|l|l|l|l|}
\hline $\mathbf{B}_{1}$ & \multicolumn{1}{|c|}{$\mathbf{C}_{\mathbf{1}}$} & $\mathbf{C}_{\mathbf{2}}$ & Weight $\boldsymbol{W}_{\boldsymbol{i}}$ \\
\hline $\mathbf{C}_{\mathbf{1}}$ & 1 & 2 & 0.667 \\
\hline $\mathbf{C}_{2}$ & $1 / 2$ & 1 & 0.333 \\
\hline
\end{tabular}

TABLE V. $\quad B_{2}-C_{i}($ I=3,4,,5) LAYER JUDGMENT MATRIX AND WEIGHT COEFFICIENT

\begin{tabular}{|l|l|l|l|l|}
\hline $\mathbf{B}_{\mathbf{2}}$ & \multicolumn{1}{|c|}{$\mathbf{C}_{\mathbf{3}}$} & \multicolumn{1}{|c|}{$\mathbf{C}_{\mathbf{4}}$} & \multicolumn{1}{c|}{$\mathbf{C}_{\mathbf{5}}$} & Weight $\boldsymbol{W}_{\boldsymbol{i}}$ \\
\hline $\mathbf{C}_{\mathbf{3}}$ & 1 & $1 / 5$ & $1 / 3$ & 0.109 \\
\hline $\mathbf{C}_{\mathbf{4}}$ & 5 & 1 & 2 & 0.582 \\
\hline $\mathbf{C}_{\mathbf{5}}$ & 3 & $1 / 2$ & 1 & 0.309 \\
\hline
\end{tabular}

TABLE VI. $\quad B_{3}-C_{i}($ I $=6,7,8)$ LAYER JUDGMENT MATRIX AND WEIGHT COEFFICIENT

\begin{tabular}{|l|l|l|l|l|}
\hline $\mathbf{B}_{\mathbf{3}}$ & \multicolumn{1}{|c|}{$\mathbf{C}_{\mathbf{6}}$} & \multicolumn{1}{|c|}{$\mathbf{C}_{\mathbf{7}}$} & \multicolumn{1}{c|}{$\mathbf{C}_{\mathbf{8}}$} & Weight $\boldsymbol{W}_{\boldsymbol{i}}$ \\
\hline $\mathbf{C}_{\mathbf{6}}$ & 1 & $1 / 4$ & $1 / 2$ & 0.136 \\
\hline $\mathbf{C}_{7}$ & 4 & 1 & 3 & 0.625 \\
\hline $\mathbf{C}_{\mathbf{8}}$ & 2 & $1 / 3$ & 1 & 0.238 \\
\hline
\end{tabular}

TABLE VII. $\quad B_{4}-C_{i}($ I=9,10) LAYER JUDGMENT MATRIX AND WEIGHT COEFFICIENT

\begin{tabular}{|l|l|l|l|}
\hline $\mathbf{B}_{\mathbf{4}}$ & $\mathbf{C}_{\mathbf{9}}$ & \multicolumn{1}{c|}{$\mathbf{C}_{\mathbf{1 0}}$} & Weight $\boldsymbol{W}_{\boldsymbol{i}}$ \\
\hline $\mathbf{C}_{\mathbf{9}}$ & 1 & 3 & 0.750 \\
\hline $\mathbf{C}_{\mathbf{1 0}}$ & $1 / 3$ & 1 & 0.250 \\
\hline
\end{tabular}

TABLE VIII. $\quad C_{6}-D_{i}(\mathrm{I}=6,7, \cdots, 13)$ LAYER JUDGMENT MATRIX AND WEIGHT COEFFICIENT

\begin{tabular}{|l|l|l|l|l|l|l|l|l|l|}
\hline $\mathbf{C}_{\mathbf{6}}$ & $\mathbf{D}_{\mathbf{6}}$ & $\mathbf{D}_{\mathbf{7}}$ & $\mathbf{D}_{\mathbf{8}}$ & $\mathbf{D}_{\mathbf{9}}$ & $\mathbf{D}_{\mathbf{1 0}}$ & $\mathbf{D}_{\mathbf{1 1}}$ & $\mathbf{D}_{\mathbf{1 2}}$ & $\mathbf{D}_{\mathbf{1 3}}$ & $\begin{array}{c}\text { Weight } \\
\boldsymbol{W}_{\boldsymbol{i}}\end{array}$ \\
\hline $\mathbf{D}_{\mathbf{6}}$ & 1 & 7 & 5 & 2 & 1 & 6 & 4 & 3 & 0.271 \\
\hline $\mathbf{D}_{\mathbf{7}}$ & $1 / 7$ & 1 & $1 / 3$ & $1 / 4$ & $1 / 6$ & 1 & $1 / 3$ & $1 / 5$ & 0.031 \\
\hline $\mathbf{D}_{\mathbf{8}}$ & $1 / 5$ & 3 & 1 & $1 / 2$ & $1 / 3$ & 3 & 1 & $1 / 4$ & 0.068 \\
\hline $\mathbf{D}_{\mathbf{9}}$ & $1 / 2$ & 4 & 2 & 1 & $1 / 6$ & 5 & 2 & 1 & 0.118 \\
\hline $\mathbf{D}_{\mathbf{1 0}}$ & 1 & 5 & 3 & 6 & 1 & 7 & 3 & 2 & 0.268 \\
\hline $\mathbf{D}_{\mathbf{1 1}}$ & $1 / 6$ & 1 & $1 / 3$ & $1 / 5$ & $1 / 7$ & 1 & $1 / 2$ & $1 / 3$ & 0.033 \\
\hline $\mathbf{D}_{\mathbf{1 2}}$ & $1 / 4$ & 3 & 1 & $1 / 2$ & $1 / 3$ & 2 & 1 & $1 / 3$ & 0.068 \\
\hline $\mathbf{D}_{\mathbf{1 3}}$ & $1 / 3$ & 5 & 4 & 1 & $1 / 2$ & 3 & 3 & 1 & 0.143 \\
\hline
\end{tabular}

TABLE IX. $\quad C_{7}-D_{i} \quad($ I $=14,15, \cdots, 21$ LAYER JUDGMENT MATRIX AND WEIGHT COEFFICIENT

\begin{tabular}{|l|l|l|l|l|l|l|l|l|l|}
\hline $\mathbf{C}_{\mathbf{7}}$ & $\mathbf{D}_{\mathbf{1 4}}$ & $\mathbf{D}_{\mathbf{1 5}}$ & $\mathbf{D}_{\mathbf{1 6}}$ & $\mathbf{D}_{\mathbf{1 7}}$ & $\mathbf{D}_{\mathbf{1 8}}$ & $\mathbf{D}_{\mathbf{1 9}}$ & $\mathbf{D}_{\mathbf{2 0}}$ & $\mathbf{D}_{\mathbf{2 1}}$ & $\begin{array}{c}\text { Weight } \\
\boldsymbol{W}_{\boldsymbol{i}}\end{array}$ \\
\hline $\mathbf{D}_{\mathbf{1 4}}$ & 1 & 8 & 6 & 3 & 1 & 7 & 3 & 2 & 0.263 \\
\hline $\mathbf{D}_{\mathbf{1 5}}$ & $1 / 8$ & 1 & $1 / 2$ & $1 / 5$ & $1 / 7$ & 1 & $1 / 4$ & $1 / 6$ & 0.027 \\
\hline $\mathbf{D}_{\mathbf{1 6}}$ & $1 / 6$ & 2 & 1 & $1 / 3$ & $1 / 4$ & 4 & 1 & $1 / 5$ & 0.055 \\
\hline $\mathbf{D}_{\mathbf{1 7}}$ & $1 / 3$ & 5 & 3 & 1 & $1 / 7$ & 6 & 3 & 1 & 0.122 \\
\hline $\mathbf{D}_{\mathbf{1 8}}$ & 1 & 7 & 4 & 7 & 1 & 5 & 4 & 3 & 0.286 \\
\hline $\mathbf{D}_{\mathbf{1 9}}$ & $1 / 7$ & 1 & $1 / 4$ & $1 / 6$ & $1 / 5$ & 1 & $1 / 3$ & $1 / 4$ & 0.028 \\
\hline $\mathbf{D}_{\mathbf{2 0}}$ & $1 / 3$ & 4 & 1 & $1 / 3$ & $1 / 4$ & 3 & 1 & $1 / 4$ & 0.065 \\
\hline $\mathbf{D}_{\mathbf{2 1}}$ & $1 / 2$ & 6 & 5 & 1 & $1 / 3$ & 4 & 4 & 1 & 0.153 \\
\hline
\end{tabular}


TABLE X. $\quad C_{8}-D_{i}(\mathrm{I}=22,23, \cdots, 29)$ LAYER JUDGMENT MATRIX AND WEIGHT COEFFICIENT

\begin{tabular}{|l|l|l|l|l|l|l|l|l|l|}
\hline $\mathbf{C}_{\mathbf{8}}$ & $\mathbf{D}_{\mathbf{1 4}}$ & $\mathbf{D}_{\mathbf{1 5}}$ & $\mathbf{D}_{\mathbf{1 6}}$ & $\mathbf{D}_{\mathbf{1 7}}$ & $\mathbf{D}_{\mathbf{1 8}}$ & $\mathbf{D}_{\mathbf{1 9}}$ & $\mathbf{D}_{\mathbf{2 0}}$ & $\mathbf{D}_{\mathbf{2 1}}$ & $\begin{array}{c}\text { Weight } \\
\boldsymbol{W}_{\boldsymbol{i}}\end{array}$ \\
\hline $\mathbf{D}_{\mathbf{2 2}}$ & 1 & 9 & 5 & 3 & 1 & 8 & 5 & 2 & 0.267 \\
\hline $\mathbf{D}_{\mathbf{2 3}}$ & $1 / 9$ & 1 & $1 / 3$ & $1 / 6$ & $1 / 8$ & 1 & $1 / 3$ & $1 / 6$ & 0.024 \\
\hline $\mathbf{D}_{\mathbf{2 4}}$ & $1 / 5$ & 3 & 1 & $1 / 4$ & $1 / 5$ & 6 & 1 & $1 / 7$ & 0.053 \\
\hline $\mathbf{D}_{\mathbf{2 5}}$ & $1 / 3$ & 6 & 4 & 1 & $1 / 8$ & 7 & 5 & 1 & 0.130 \\
\hline $\mathbf{D}_{\mathbf{2 6}}$ & 1 & 8 & 5 & 8 & 1 & 6 & 4 & 2 & 0.279 \\
\hline $\mathbf{D}_{\mathbf{2 7}}$ & $1 / 8$ & 1 & $1 / 6$ & $1 / 7$ & $1 / 6$ & 1 & $1 / 4$ & $1 / 6$ & 0.022 \\
\hline $\mathbf{D}_{\mathbf{2 8}}$ & $1 / 5$ & 3 & 1 & $1 / 5$ & $1 / 4$ & 4 & 1 & $1 / 6$ & 0.051 \\
\hline $\mathbf{D}_{\mathbf{2 9}}$ & $1 / 2$ & 6 & 7 & 1 & $1 / 2$ & 6 & 6 & 1 & 0.175 \\
\hline
\end{tabular}

C. rank ordering (calculate the weight vector) and inspection When $\mathrm{n}$ equals 1 to 9,RI given by Satty are shown in TABLE XI

TABLE XI. RIVALUE TABLE

\begin{tabular}{|c|c|c|c|c|c|c|c|c|c|}
\hline $\mathbf{n}$ & $\mathbf{1}$ & $\mathbf{2}$ & $\mathbf{3}$ & $\mathbf{4}$ & $\mathbf{5}$ & $\mathbf{6}$ & $\mathbf{7}$ & $\mathbf{8}$ & $\mathbf{9}$ \\
\hline $\mathbf{R I}$ & 0 & 0 & 0.58 & 0.90 & 1.12 & 1.24 & 1.32 & 1.41 & 1.45 \\
\hline
\end{tabular}

Of coincidence test, by formula $\mathrm{CI}=(\lambda \max -\mathrm{n}) /(\mathrm{n}-1)$, we know $\mathrm{CI}=(4.158-4) /(4-1)=0.053$, Table. 11 shows that when $\mathrm{n}=4$, $\mathrm{RI}=0.9$, and by formula $\mathrm{CR}=\mathrm{CI} / \mathrm{RI}=0.053 / 0.9=0.059<0.1$, so the consistency of judgment matrix of the target layer and rule layer is satisfied.

The same can be: CR of judgment matrix $\mathrm{B} 1-\mathrm{Ci}$ is 0.000 , CR of judgment matrix B2-Ci is 0.003, CR of B3-Ci is 0.016, $\mathrm{CR}$ of judgment matrix $\mathrm{B} 4-\mathrm{Ci}$ is $0.000, \mathrm{CR}$ of judgment matrix C6-Di is 0.038, CR of judgment matrix C7-Di is 0.062, CR of judgment matrix C8-Di is 0.084 , they all less than 0.1 , so the consistency of all judgment matrixes are satisfied.

\section{The weight of each index and the comprehensive weights}

On the basis of above, finally we get the weights of the whole index system and their comprehensive weights, the results are shown in TABLE I.

\section{APPLICATION EXAMPLES}

Using AHP to evaluate 40 cases of online public opinion randomly selected in 2012.They are island fishing operations, electric business price war, Chinese children test of transgenic rice, Beijing storm, Liu Xiang incidents, Yiliang earthquake, Yang Dacai "smile" cousin, Diaoyutai parade, Zhou Kehua Chongqing door event, serious traffic accident of Yanan, Shenyang shops closed, Chongqing beauty, Suzhou building long underwear Tucao, events in Shifang, Harbin Yangming beach bridge collapse, big fire in Jixian County in Tianjin, China Southern airline stewardess is hit, Wuhan elevator falling accident, Bo Xilai series of cases, the earthquake of Yangzhou in Jiangsu, Guangzhou Yuexiu District Committee hit airline stewardess, teacher's Day gifts, Macheng own desk incident, Panzhihua coal mine explosion, President of PKU Zhou Qifeng kneel female, Hangzhou housing collapse, Zou Hengfu revealed the promiscuous event of PKU, Panjin demolition shooting events, group events in Qidong, Beijing Metro knife hijacked, hawker hold urban management thigh, Yunnan serial disappearance, the US say no to Confucius Institute, Wang Laoji trademark case, eat empty rates businesswoman turned the county leaders, former badminton champion airspace rates, vice mayor, deputy director of cycling hold a gun beat reporters. Introducing normalization method to make indexes being dimensionless before calculation, and it makes the comparability of scoring stronger. The formula of the comprehensive score (we mark it as OM) is:

$$
\mathrm{OM}=\Sigma^{31} \omega_{1} \beta_{1}
$$

For wi is the weight of each index, $\beta \mathrm{i}$ is the normalized value of the score of online public opinion in the index, the results as shown in TABLE XII.

TABLE XII. THE SCORE OF ONLINE PUBLIC OPINION EVALUATION

\begin{tabular}{|c|c|}
\hline events & score \\
\hline island fishing operations & 0.5677 \\
\hline electric business price war & 0.1828 \\
\hline Chinese children test of transgenic rice & 0.0902 \\
\hline Beijing storm & 0.4741 \\
\hline Liu Xiang incidents & 0.2718 \\
\hline Yiliang earthquake & 0.0762 \\
\hline Yang Dacai "smile" cousin & 0.1593 \\
\hline Diaoyutai parade & 0.2162 \\
\hline Zhou Kehua Chongqing door event & 0.0678 \\
\hline serious traffic accident of Yanan & 0.0326 \\
\hline Shenyang shops closed & 0.1446 \\
\hline Chongqing beauty & 0.0295 \\
\hline Suzhou building long underwear Tucao & 0.0239 \\
\hline events in Shifang & 0.0243 \\
\hline Harbin Yangming beach bridge collapse & 0.0232 \\
\hline big fire in Jixian, Tianjin & 0.0115 \\
\hline China Southern airline stewardess is hit & 0.0149 \\
\hline Wuhan elevator falling accident & 0.0113 \\
\hline Bo Xilai series of cases & 0.1365 \\
\hline the earthquake of Yangzhou in Jiangsu & 0.0601 \\
\hline $\begin{array}{llllll}\begin{array}{l}\text { Guangzhou } \\
\text { stewardess }\end{array} & \text { Yuexiu } & \text { District } & \text { Committee } & \text { hit airline } \\
\end{array}$ & 0.0097 \\
\hline teacher's Day gifts & 0.0068 \\
\hline Macheng own desk incident & 0.0146 \\
\hline Panzhihua coal mine explosion & 0.0046 \\
\hline President of PKU Zhou Qifeng kneel female & 0.0154 \\
\hline Hangzhou housing collapse & 0.0051 \\
\hline Zou Hengfu revealed the promiscuous event of PKU & 0.0034 \\
\hline Panjin demolition shooting events & 0.0066 \\
\hline
\end{tabular}




\begin{tabular}{|l|l|}
\hline group events in Qidong & 0.0036 \\
\hline Beijing Metro knife hijacked & 0.0158 \\
\hline hawker hold urban management thigh & 0.0047 \\
\hline Yunnan serial disappearance & 0.2096 \\
\hline the US say no to Confucius Institute & 0.0270 \\
\hline Wang Laoji trademark case & 0.0861 \\
\hline eat empty rates businesswoman turned the county leaders & 0.0316 \\
\hline former badminton champion airspace rates & 0.0368 \\
\hline vice mayor rides his daughter & 0.2646 \\
\hline deputy director of cycling hold a gun beat reporters & 0.0516 \\
\hline cooking oil rise in price & 0.0770 \\
\hline nutritious lunch in Jinzhai, Anhui & 0.0027 \\
\hline
\end{tabular}

From TABLE XII , 40 cases of online public opinion randomly selected in 2012, the score in the top three are island fishing operations, Beijing storm, Liu Xiang incidents, and they are involved in the state sovereignty, the capital of catastrophic accidents, sports stars for their journey to arise suddenly event, have caused the most extensive attention, the score in accordance with the reality effect of the online public opinion, it has stronger rationality.

\section{CONCLUSIONS}

This article constructs the index system of online public opinion from four aspects; they are the sensitivity of online public opinion, the strength of online public opinion, the information activity of online public opinion and the emotional tendency of online public opinion. To use AHP method to determine each index weight and establish the influence degree of each index on the online public opinion pre-warning. The effect degree from high to low is: sensitivity of online public opinion> the information activity of online public opinion> emotional tendency of online public opinion> the strength of online public opinion. Finally, using example to verify the analytic hierarchy process to the index system of evaluation has strong rationality. It provides a new method to solve the online public opinion pre-warning.

\section{ACKNOWLEDGEMENTS}

This research is financially supported by the Fundamental Research Funds for the Central Universities (Grant No. 2012IB-003).

\section{REFERENCES}

[1] Wenjing Li.Design and Analysis of Index System of Online Public Opinion[J].Information Science,2009,27(7):986-991

[2] Yuan Dai, Xiaowei Hao, Yan Guo. Research on Security Evaluation Indicator System of Internet Public Opinion in China[J]. Netinfo Security,2010,(4):12-15.

[3] Juling Ding, Zhongjian Le, Gensheng Wang. A Survey on Internet Public Opinions Crisis Warning in China[J]. Journal of Information,2010, 29(10): 5-8.

[4] Shaozhong Wu, Shuhua Li. Study on machine-processed of online public opinion pre-warming [J]. Journal of Chinese People's Public Security University(Science and Technology),2008,(3):38-42.

[5] Yuan Dai, Fei Yao. Study on mining the information and evaluation index system based on online public opinion [J]. Information Studies:Theory \& Application, 2008,31(6):873-876.

[6] Youngsang Cho, Junseok Hwang, Daeho Lee. Identification of effective opinion leaders in the diffusion of technological innovation: A social network approach[J].Technological Forecasting and Social Change, 2012,79(1):97-106.

[7] Carolin K, Sabine S, Freimut B. Warning system for online market research Identifying critical situations in online opinion formation [J]. Knowledge-Based Systems,

2011,24(6):824-83 
TABLE I. EACH INDEX WEIGHT OF ONLINE PUBLIC OPINION AND COMPREHENSIVE WEIGHT

\begin{tabular}{|c|c|c|c|c|c|c|c|}
\hline Target layer & $\begin{array}{l}\text { Criterion } \\
\text { layer (B) }\end{array}$ & weight & Factor layer(C) & weight & Index layer (D) & weight & $\begin{array}{l}\text { Comprehensive } \\
\text { Weight of index }\end{array}$ \\
\hline \multirow{31}{*}{ 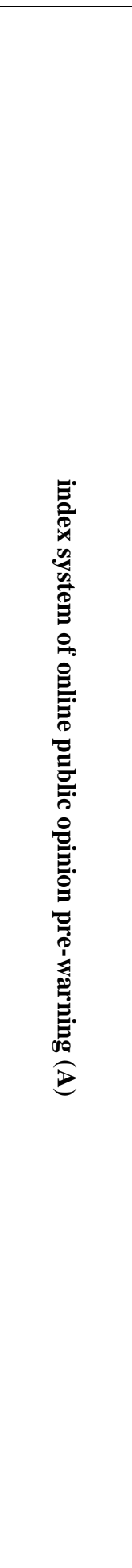 } & \multirow{2}{*}{$\begin{array}{l}\text { sensitivity of } \\
\text { online public } \\
\text { opinion ( }\left(\mathrm{B}_{1}\right)\end{array}$} & \multirow{2}{*}{0.524} & Content sensibility $\left(\mathrm{C}_{1}\right)$ & 0.667 & $\begin{array}{l}\text { Degree of content } \\
\text { sensibility }\left(D_{1}\right)\end{array}$ & 1 & 0.350 \\
\hline & & & Figure sensibility $\left(\mathrm{C}_{2}\right)$ & 0.333 & $\begin{array}{ll}\begin{array}{l}\text { Degree of } \\
\text { sensibility }\left(D_{2}\right)\end{array} & \text { figure } \\
\end{array}$ & 1 & 0.174 \\
\hline & \multirow{3}{*}{$\begin{array}{l}\text { strength of } \\
\text { online public } \\
\text { opinion }\left(B_{2}\right)\end{array}$} & \multirow{3}{*}{0.054} & $\begin{array}{l}\text { Breadth of Channels of } \\
\operatorname{spread}\left(C_{3}\right)\end{array}$ & 0.109 & $\begin{array}{l}\text { Diversity of spread } \\
\text { channels }\left(\mathrm{D}_{3}\right)\end{array}$ & 1 & 0.006 \\
\hline & & & Gross Cyber citizen $\left(\mathrm{C}_{4}\right)$ & 0.582 & $\begin{array}{l}\text { Total number of involved } \\
\text { netizen }\left(\mathrm{D}_{4}\right)\end{array}$ & 1 & 0.031 \\
\hline & & & $\begin{array}{l}\text { The regional distribution } \\
\text { of netizen }\left(C_{5}\right)\end{array}$ & 0.309 & $\begin{array}{l}\text { Geographic distribution of } \\
\text { netizen }\left(D_{5}\right)\end{array}$ & 1 & 0.017 \\
\hline & \multirow{24}{*}{$\begin{array}{l}\text { information } \\
\text { activity of } \\
\text { online public } \\
\text { opinion } \\
\left(\mathrm{B}_{3}\right)\end{array}$} & \multirow{24}{*}{0.325} & \multirow{8}{*}{$\begin{array}{l}\text { The news channel of } \\
\text { information activity }\left(\mathrm{C}_{6}\right)\end{array}$} & \multirow{8}{*}{0.136} & $\begin{array}{l}\text { sum of publishing news } \\
\left(D_{6}\right)\end{array}$ & 0.271 & 0.012 \\
\hline & & & & & $\begin{array}{l}\text { Amount of news browsing } \\
\left(D_{7}\right)\end{array}$ & 0.031 & 0.001 \\
\hline & & & & & $\begin{array}{l}\text { Sum of evaluating } \\
\text { news }\left(D_{8}\right)\end{array}$ & 0.068 & 0.003 \\
\hline & & & & & $\begin{array}{l}\text { Sum of reprinting news } \\
\left(D_{9}\right)\end{array}$ & 0.118 & 0.005 \\
\hline & & & & & $\begin{array}{l}\text { Change rate of news } \\
\text { released }\left(D_{10}\right)\end{array}$ & 0.268 & 0.012 \\
\hline & & & & & $\begin{array}{l}\text { Change rate of news } \\
\text { browse }\left(D_{11}\right)\end{array}$ & 0.033 & 0.001 \\
\hline & & & & & Change rate of news $\left(D_{12}\right)$ & 0.068 & 0.003 \\
\hline & & & & & $\begin{array}{l}\text { Change rate of news } \\
\text { reprint }\left(\mathrm{D}_{13}\right)\end{array}$ & 0.143 & 0.006 \\
\hline & & & \multirow{8}{*}{$\begin{array}{l}\text { Forum channel of } \\
\text { information activity }\left(\mathrm{C}_{7}\right)\end{array}$} & \multirow{8}{*}{0.625} & $\begin{array}{l}\text { total number of posting } \\
\text { BBS }\left(D_{14}\right)\end{array}$ & 0.263 & 0.053 \\
\hline & & & & & $\begin{array}{l}\text { total number of clicking } \\
\text { BBS }\left(D_{15}\right)\end{array}$ & 0.027 & 0.005 \\
\hline & & & & & $\begin{array}{l}\text { total number of following } \\
\text { BBS }\left(D_{16}\right)\end{array}$ & 0.055 & 0.011 \\
\hline & & & & & $\begin{array}{l}\text { total number of } \mathrm{BBS} \\
\text { reprint }\left(\mathrm{D}_{17}\right)\end{array}$ & 0.122 & 0.025 \\
\hline & & & & & $\begin{array}{l}\text { Change rate of BBS post } \\
\left(D_{18}\right)\end{array}$ & 0.286 & 0.058 \\
\hline & & & & & $\begin{array}{l}\text { Change rate of BBS reprint } \\
\text { click }\left(D_{19}\right)\end{array}$ & 0.028 & 0.006 \\
\hline & & & & & $\begin{array}{l}\text { Change rate of BBS follow } \\
\left(D_{20}\right)\end{array}$ & 0.065 & 0.013 \\
\hline & & & & & $\begin{array}{l}\text { Change rate of } \\
\text { reprint }\left(\mathrm{D}_{21}\right)\end{array}$ & 0.153 & 0.031 \\
\hline & & & \multirow[t]{8}{*}{$\begin{array}{l}\text { Micro-blog channel of } \\
\text { information activity }\left(\mathrm{C}_{8}\right)\end{array}$} & \multirow{8}{*}{0.238} & $\begin{array}{l}\text { Total number of } \\
\text { tweeting }\left(\mathrm{D}_{22}\right)\end{array}$ & 0.267 & 0.021 \\
\hline & & & & & $\begin{array}{l}\text { Sum of reading Micro-blog } \\
\left(D_{23}\right)\end{array}$ & 0.024 & 0.002 \\
\hline & & & & & $\begin{array}{l}\text { Sum of } \\
\text { comment }\left(\mathrm{D}_{24}\right)\end{array}$ Micro-blog & 0.053 & 0.004 \\
\hline & & & & & $\begin{array}{l}\text { Sum of Micro-blog } \\
\text { reprint }\left(D_{25}\right)\end{array}$ & 0.130 & 0.010 \\
\hline & & & & & $\begin{array}{l}\text { Change rate of } \\
\text { tweeting }\left(D_{26}\right)\end{array}$ & 0.279 & 0.022 \\
\hline & & & & & $\begin{array}{l}\text { Change rate of reading } \\
\text { Micro-blog }\left(D_{27}\right)\end{array}$ & 0.022 & 0.002 \\
\hline & & & & & $\begin{array}{l}\text { Change rate of Micro-blog } \\
\text { comment }\left(\mathrm{D}_{28}\right)\end{array}$ & 0.051 & 0.004 \\
\hline & & & & & $\begin{array}{l}\text { Change rate of Micro-blog } \\
\text { reprint }\left(D_{29}\right)\end{array}$ & 0.175 & 0.014 \\
\hline & \multirow{2}{*}{$\begin{array}{l}\text { Emotional } \\
\text { tendency of } \\
\text { online public } \\
\text { opinion }\left(\mathrm{B}_{4}\right)\end{array}$} & \multirow{2}{*}{0.097} & Attitude tendency $\left(\mathrm{C}_{9}\right)$ & 0.61 & $\begin{array}{l}\text { Opinion tendency of } \\
\text { netizen }\left(\mathrm{D}_{30}\right)\end{array}$ & 1 & 0.059 \\
\hline & & & Behavior tendency $\left(\mathrm{C}_{10}\right)$ & 0.39 & $\begin{array}{l}\text { Action tendency of } \\
\text { netizen }\left(\mathrm{D}_{31}\right)\end{array}$ & 1 & 0.038 \\
\hline
\end{tabular}

